\title{
Improving Creative Thinking in Engineering Students Through Art Appre- ciation
}

\author{
Patricia Caratozzolo, School of Engineering and Sciences, Tecnologico de Monterrey, Mexico
}

Patricia Caratozzolo was born in Buenos Aires, Argentina. She received the Ph.D. degree from the Universitat Politécnica de Catalunya, Barcelona, Spain, in 2003. Since 2005 she has been a member of the faculty of Tecnológico de Monterrey, Campus Santa Fe, where she is Assistant Professor of Power Energy Systems in the Mechatronics and Sustainable Development Department. She is leading different projects in the area of educational innovation, teaching-learning strategies, Fourth Industrial Revolution, Critical Thinking, Cognitive Flexibility and development of soft skills in engineering. She teaches courses on the implementation of Educational Innovation strategies as: Development of Creativity and Innovation Techniques, Development of Transversal Skills and Competencies, Development of Critical Thinking and Case Analysis, Problem Solving through Lateral Thinking and Design Thinking. Dr. Caratozzolo is Senior Member of IEEE and member of the IEEE Industry Applications Society (IAS), Power and Energy Society (PES) and Women in Engineering (WIE). She is also a member of the International Association of Continuing Engineering Education (IACEE). pcaratozzolo@ tec.mx

Alvaro Alvarez-Delgado, Language Department, School of Social Sciences, Tecnologico de Monterrey, Mexico

Alvaro Alvarez-Delgado was born in San Luis Potosi, Mexico. He obtained his PhD in Hispanic Literature from El Colegio de Mexico in 2009 with the thesis, Compañeros de viaje (1959): The First Jaime Gil de Biedma. Since 2009, he has been a member of the faculty at Tecnologico de Monterrey, Santa Fe campus, in the Languages Department from the School of Education and Humanities. He is the Coordinator at the Writing Center, Santa Fe Campus. His literary interests are related to literature written by women from the middle '50's to the middle '70's in Mexico, especially focused on the works by Elena Garro. His primary areas of interest are vocabulary enrichment, critical reading, literary criticism and the function of fine art appreciation as cognitive tools. Dr. Alvarez-Delgado is member of the Fundación Garro y Paz and has been the senior editor for the dramatic work by Elena Garro, besides being both the Coordinator and the Ambassador at Campus Santa Fe for the Academic Integrity Committee.

\section{Samira Hosseini, Writing Lab, Center for Educational Innovation, Tecnológico de Monterrey, Mexico}

Samira Hosseini obtained her BSc degree in Applied Physics from the University of North Tehran, Iran, and her MSc degree in Polymer Chemistry and a $\mathrm{PhD}$ degree in Biomedical Engineering from the University of Malaya, Kuala Lumpur, Malaysia. She served as a postdoctoral associate at Tecnologico de Monterrey, Mexico while holding a postdoctoral fellowship at Massachusetts Institute of Technology, Cambridge, USA. Currently, she is Director of Writing Lab in the Center for Educational Innovation at Tecnologico de Monterrey, Mexico. She also holds the position of research professor at the School of Engineering and Sciences, Tecnologico de Monterrey, Mexico. She is the author/co-author of more than 25 scientific publications, 19 book chapters and is the inventor/co-inventor of 4 intellectual properties. She is a member of the Mexican National Academy of Researchers (level one) and is on the Editorial Board of various international journals. 


\title{
Improving creative thinking in engineering students through art appreciation
}

\begin{abstract}
Creativity thinking is a metacognitive process that allows not only complex problem solving but also a high degree of innovation that future engineers would need to perform disruptive tasks successfully. Given the difficulty that comes with the enhancement of a creative perspective using logical-scientific modality of thought, a need arises to consider disruptive innovations in teaching-learning approaches for new engineering programs. In this study, engineering students were given necessary trainings in creative thinking techniques in order for them to comply with: (i) acquiring competencies for a high degree of innovation; (ii) exploring through directions unknown and potentially risky and, (iii) embracing contradictions and integrating divergent perspectives and ideas. Different cognitive theories were used, specifically adapted for engineering students: firstly, theory of cognitive functioning and development of thoughts via artistic-narrative modality was taken into consideration. Secondly, the theory of mind development for integrating education across subjects were used as the basis of this study. The research was conducted using an experimental methodology with a sample size of 168 engineering students. To assess creative thinking competencies in a broad range of engineering work activities, the VALUE rubrics of the American Association of Colleges and Universities, AAC\&U, were applied. The obtained results have shown that the designed approach promoted both desired abilities, a better understanding of scientific concepts among engineering students and also a higher capability to transform ideas and solutions into entirely new forms.
\end{abstract}

\section{Keywords}

Creative thinking, cognitive and metacognitive tools, STEAM, educational innovation, higher education.

\section{Introduction}

The Future of Jobs report released by the World Economic Forum [1] includes a table of the skills required by future professionals in order to face the challenge of the Fourth Industrial Revolution. The report uses the concept of skills stability to illustrate the degree to which, by the year 2020, particular occupations and job types are expected to require competence in new skills that have not been part of that occupation's skill core set before. Creativity, which was in tenth place in 2015 assessment, occupies the third place in the 2020 list, as shown in Table 1. Creativity thinking is defined as the metacognitive process that allows not only complex problem solving but also promotes a high degree of innovation [2]. In this sense, it is essential to strengthen this competence in the training of future engineers, with the objective of enabling them to perform disruptive tasks successfully and to confront problems for which they have not learned solutions. 
TABLE 1. World Economic Forum Report

\begin{tabular}{|c|c|c|}
\hline \multicolumn{3}{|c|}{ Top 10 Skills in } \\
\hline & 2020 & 2015 \\
\hline 1 & Complex Problem Solving & Complex Problem Solving \\
\hline 2 & Critical Thinking & Coordinating with Others \\
\hline 3 & Creativity & People Management \\
\hline 4 & People Management & Critical Thinking \\
\hline 5 & Coordinating with others & Negotiation \\
\hline 6 & Emotional intelligence & Quality Control \\
\hline 7 & Judgment \& Decision Making & Service Orientation \\
\hline 8 & Service Orientation & Judgment \& Decision Making \\
\hline 9 & Negotiation & Active Listening \\
\hline 10 & Cognitive Flexibility & Creativity \\
\hline
\end{tabular}

The concept of STEM was coined almost 20 years ago and describes the integration of Science, Technology, Engineering and Mathematics in the educational curriculum [3]. The first STEM models incorporated disciplines along with project-based learning. In the case of engineering programs, they also incorporate design elements to combine function and form [4]. The engineering design implies a systematic process in an rigid framework, with the aim of obtained a sustainable realization of a product, a specified set of constraints that meet the client's needs, and a higher level of quality specifications. However, the issue of the specific quality component related to disruptive innovation and product aesthetics continued to be a pending issue of engineering design.

The key question was: How to include creative thinking in an engineering design process with higher order logical components? This showed to be a problem of Western culture, since it tends to separate the scientific from the humanistic thinking processes. In response to this paradigm, the academic community started to recognize the value of art and imagination in the process of generating scientific knowledge. One original idea for extending the STEM approach to integrate art and design was proposed by Georgette Yakman in 2008, and was an andragogy approach consisted to develop Science, Technology, Engineering, Art and Mathematics in STEAM Projects $[5,6]$. The obtained results showed that STEAM approaches do promoted a better understanding of scientific concepts in engineering subjects but not a higher capability to transform ideas and solutions into entirely new forms because they do not consider the explicit development of both principles of the theory of creative experience, which are continuity and interaction [7].

As Mihaly Cskszentmihalyi established in 1996, creative ideas arise from the synergy of many sources, and not only from the mind of an isolated person. A creative achievement is almost never the result of a sudden intuition, but comes after years of hard work [8]. Current initiatives consider that all actions designed to increase creative thinking should be implemented in crosscurricular form and with interdisciplinarity, so that the development of this soft skill in students occurs incrementally, course by course, as throughout each higher education program $[9,10,11]$. 
Our project consisted in giving engineering students the training in creative thinking techniques to address the world's challenges with a high degree of innovation, considering that creative thinking is more complex than divergent thinking. The cognitive and metacognitive tools were designed considering that creativity requires both sensitivity to problems and abilities to redefine approaches. The results showed the incremental acquisition of a creative thinking beyond subjections to functional fixedness, typical cognitive bias of engineering students $[7,8]$.

\section{Creative thinking in engineering programs}

Product design is a scientific discipline of engineering that aims to solve problems for the realization of artifacts that serve specific purposes. Engineering design differs from artistic design as the process is not free in expression but systematic and rational, and involves higher order logical components and concepts. There is a false perception that engineers should use only the principles of criticality instead of creativity, however, emotions and aesthetics enrich the solutions provided to the problems since it is impossible to judge criticality that is based solely on rational arguments [4].

It is important to note that critical thinking is not enough to cover the complexity of problem solving, especially when it comes to empowering the process of knowledge construction, since knowledge is a process built in stages. From the epistemological point of view, the construction of knowledge should contemplate different approaches in each of the phases that comprise it [12]:

- in the divergent phase (with emphasis on the generation of a large number of ideas regardless of their quality) only a creative thinking ensures that the process is divergent, generative, constructive, out-of-the-box, and non-judgmental.

- in the convergent phase (with emphasis on quality by discarding unpractical ideas), the exercise of critical thinking is required to ensure that the process is selective, analytical, systematic, evaluative and rational.

A knowledge-driven learning strategy should include activities and didactics that will develop in students their ability to know when to apply each of the two modalities of thinking, logicalmathematical or artistic-narrative, depending on the circumstance. To date, traditional teaching schemes not only fostered the culture of individual performance but also prioritized rational thinking, and avoided incorporation of the artistic-narrative modality in engineering courses in an attempt to the rigor of the search for empirical truth. The use of cognitive tools for the development of the abilities of creative thinking must be complemented with the application of metacognitive tools in order to also influence the development of specific dispositions of temperament, that is, the exercise of reflection skills in engineering students [13].

The study hypothesis was that the exercise of art criticism and aesthetic judgment fosters the appearance of such specific dispositions of the temperament necessary for a substantial increase in the abilities of creative thinking in students. 
The desired abilities considered were [14]:

- the capacity to combine or synthesize existing ideas, images, or expertise in original ways

- the experience of thinking, reacting, and working in an imaginative way

- a high degree of innovation, divergent thinking, and risk taking

This study shows that the inclusion of artistic spaces for reflection are also very appropriate because they avoid the concept of utilitarianism and functionality in design, which prevails in spaces for scientific reflection. The advantage of working with artistic spaces is that the fine art artifact is considered a non-utilitarian aesthetic object and has no functional purpose except to be intervened and to awaken in students unexpected kinds of aesthetic judgments in addition to strengthen their curiosity, imagination and the formation of personal opinion.

\section{Cognitive theories}

Different cognitive theories were used in this study, specially adapted for engineering students. Firstly, the theory of cognitive functioning of Jerome Bruner for students' development via the artistic-narrative modality was used. This theory deals with students' ability to find meaning in artworks, and to develop new technological products through conversion of the imaginative concepts into a dependable reality [15]. Secondly, the theory of mind development by John Dewey was used, integrating education across subjects and engaging students with real-world applications in order to form their proper judgments and to increase their practical knowledge [16].

Jerome Bruner points out that there are two modalities of cognitive functioning of thought, and each of them offers characteristic ways of constructing reality and ordering experience: The logical-scientific modality tries to fulfill the ideal of a mathematical, formal system of description and explanation. It uses the categorization or conceptualization and the operations by which the categories are established, represented, idealized and related to each other in order to build a system. In general terms, the logical-scientific modality uses procedures to ensure verifiable references, and to verify empirical truth. This is the modality in which engineering students are typically trained at college. The field of engineering is defined not only by observable entities to which their basic statements refer, but also by the series of possible worlds that can be generated logically and verified against observable entities directed by hypothesis of principles.

The artistic-narrative modality, on the other hand, looks for particular connections between two events and uses procedures to establish the likelihood, not the truth. The artistic-narrative modality is concerned with how we perceive meaning for an experience, and deals with human intentions and actions and the vicissitudes and consequences that mark its course. It tries to situate the events of experience in time and space. This type of modality is typically offered to students of artistic and humanistic programs in college. 


\section{Cognitive and metacognitive tools}

Metacognitive knowledge consists of learning strategies which students can use to regulate the process of knowledge acquisition. Creative thinking does not occur automatically. Such successful creative process depends not only on the cognitive effort but also on the metacognitive processing, which in turn depends on the development stage of the student. Due to the fact that in the same classroom students with different levels of cognitive development coexist, we have considered two fundamental concepts derived of Vygotsky's work, Scaffolding and Zone of Proximal Development [17]:

Scaffolding concept. It refers to the observed fact that when a teacher interacts with students with the intention of teaching, they tend to adapt the degree of help to the level of competence they perceive of themselves.

Zone of Proximal Development (ZPD) concept. The ZPD is the gap between the real development level of the students (determined by the independent solution to the problems) and, the level of potential development (determined by the solution to the problems with the teacher's guide or with the support of the classmates).

The cognitive tools chosen for the development of the artistic-narrative modality consider the practice of art criticism and aesthetic judgment about several selected expressions of the fine arts such as architecture, design and sculpture. Two concepts were considered for the design of the activities in which those cognitive tools were applied: the theory of specificity by Robert Ennis' domain and, the framework of Paul Torrance's work.

Creative thinking and the specificity of the domain [18]

An adaptation of the conceptual contribution of Ennis's on critical thinking was used considering that creative thinking, like critical thinking, is characterized by three principles:

- Background knowledge is essential for creative thinking in a given domain.

- Transfer of creative thinking between domains becomes possible when accompanied by an instruction for such transfer.

- Strong or even moderate specificity instruction is likely to be more effective than general creative thinking instructions in the form of subsequent add-ons.

Torrance framework [19]

Creative thinking refers to the production of:

- Fluency, or the production of a great number of relevant ideas

- Originality, or the generation of unique, uncommon or unusual ideas in a given context

- Flexibility, or the incorporation of different perspectives and points of view and in different categories/spectra of thinking

- Elaboration, or the capacity to enhance the ideas by providing additional detail

The best strategy for the incorporation of the activities was in the form of didactic interventions and integrated infusion-immersion approach in ordinary courses of the engineering program [20,21]. The activities were designed considering the actual cognitive stages of thinking of the students, according to Kieran Egan's theory [23], and incorporated analysis sessions of fine art 
along with appreciation and critic of artistic masterpieces, including selected works of architecture, artistic designs and sculptures. All artistic activities included in this project aimed to expose the engineering students to the concepts of appropriation, deconstruction, decontextualization, redefinition, and dislocation of the artifacts so that they leave the position of spectators and become involved as creators [20]. By encouraging them not to passively wait for an explanation about the art object they were trained in their ability to understand, translate and encode symbolic information and to elaborate their own concepts and constructs through abstract reasoning.

\section{Methodology}

\section{Participants}

Participants were 168 undergraduate students of engineering programs. They joined the study voluntarily, and 130 of them underwent metacognitive instruction, while 38 students remained untrained (control group). Participants who contributed to this study had an average age of 22 years, and were distributed in five different courses taught by the first author (C001-C005). A total of 8 different courses were involved over 5 semesters (S1-S5), from January 2016 to May 2017, as shown in Table 2.

TABLE 2. Methodology data used in this study.

\begin{tabular}{lcccc}
\hline $\begin{array}{c}\text { Group } \\
\text { Type }\end{array}$ & $\begin{array}{c}\text { Total } \\
\text { sample }\end{array}$ & $\#$ & $\begin{array}{c}\text { Students } \\
\text { per } \\
\text { course }\end{array}$ & $\begin{array}{c}\text { Course \& } \\
\text { Semester } \\
\text { IDs }\end{array}$ \\
\hline \multirow{2}{*}{ EG-PreTest-T } & 67 & 1 & 24 & C001-S1 \\
\cline { 3 - 5 } & & 3 & 15 & C002-S2 \\
\hline CG-PreTest & 20 & 4 & 20 & C001-S5 \\
\hline \multirow{2}{*}{ EG-T } & & 5 & 21 & C004-S1 \\
\cline { 2 - 5 } & 63 & 6 & 23 & C002-S4 \\
\hline CG & 18 & 8 & 19 & C001-S4 \\
\hline & 168 & & & C005-S3 \\
\hline
\end{tabular}

\section{Instrumentation}

Three different types of instruments were used [24]. The first type was vocabulary tests, with multiple-choice and true or false questions designed to establish the approximate art lexicon of each student, compared to different glossaries of art terms [25]. The second type was a set of art critique worksheets, art crit cards [26,27]. Assessing the evidence for competencies as creative and divergent thinking typically involves subjective judgments concerning products or behaviors, hence the need to use a third type of instrument, adapted from an already-existing rubric, the VALUE Rubrics, from AAC\&U, developed for the Essential Learning Outcomes of the Association of American Colleges and Universities [28]. The AAC\&U rubric was used to assess how well students performed each outcome. The other instruments for data collection and the group criteria were the following: 
PreTest: Vocabulary test regarding Glossary of Art Terms

Treatment: Four step method for Art criticism and Aesthetic judgment [19], in Table 3

PostTest: Art crit cards (with vocabulary tests included) and Value Rubrics by AAC\&U

EG-PreT-T: Experimental Group with PreTest and Treatment

EG-T: Experimental Group without PreTest, only Treatment

CG-PreT: Control Group with PreTest

$C G$ : Control Group without PreTest

\section{Procedure}

The research methodology of the project was quantitative-experimental. Of the 168 students tested, 130 were part of the experimental group (EG) and 38 of the control group (CG). Of the 130 EG students, 67 students received PreTest and Treatment (EG-PreT-T) and 63 students received only treatment, EG-T. Of the 38 students in the control group, 20 received the PreTest, $C G$-PreT, and of the remaining 18 students neither received vocabulary or critical thinking instruction, $\mathrm{CG}$.

\section{Design}

The design chosen for the project was focused on the experimental research, quantitative analysis, Solomon type [29]. It was intended to control the possible interaction that could exist between the PreTest and the Treatment. This design allowed the results to be generalized also for the subjects who had not receive the PreTest. Two groups have received PreTest while other two have not. Likewise, two groups have received Treatment while other two have not. The measurement of the dependent variable in PreTest situation was asynchronously performed among the two groups, and the measurement of the dependent variable in PostTest situation was asynchronously performed among the four groups. The subject assignment to the groups was done randomly. The methodological design is schematically explained in Fig. 1. In each semester, the students of the experimental group attended three sessions of practicing art criticism and aesthetic judgment. The chosen topics were selected from different chapters of an art blog page previously release by the instructors of the courses involved.

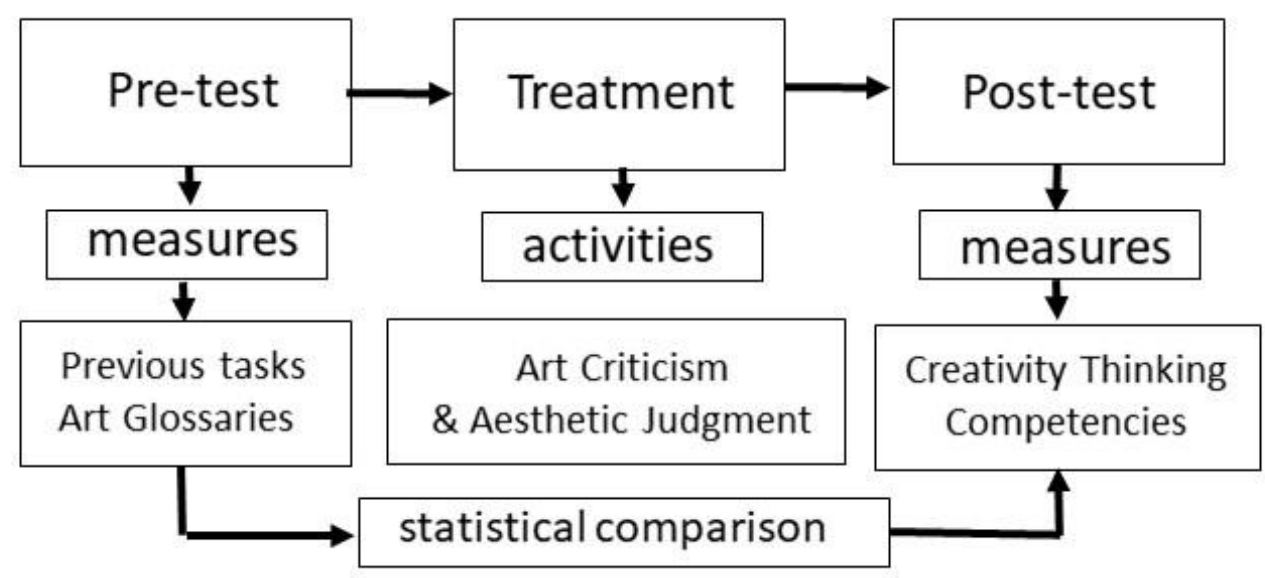

Figure 1. Procedure design 
The example included in the next section describes, in succinct form, an example of activity developed with a group of students using cognitive and metacognitive tools, and some strategies of metacognitive instruction, to develop creative thinking, using both concepts: Scaffolding and ZPD.

The aim of the study was not to measure the creative level of the students but to evaluate the correlation between the exercise of those concrete artistic activities and the increase of creative thinking. Because of that the Torrance TCTT tests [19] were not part of none PostTest, and instead AAC\&U rubric showed in Table 8 was applied.

\section{Art appreciation activity}

Art is the creative process par excellence and is an ideal tool to clarify the concept of ambiguity in engineering students, who are usually exposed to logical-scientific-based modality. In this way, specific metacognitive tools were considered to develop creative thinking and to enhance the capacity for analysis and combination of existing ideas and images through new disruptive and alternative solutions [30,31].

Work: Fluxkit [32]

Artist: Jurgis Maciunas (1931-1978), American artist born in Lithuania

Year: 1965

Description: It is a briefcase covered with vinyl that contains objects made in different media, designed and assembled by Maciunas.

It is currently exposed in MOMA, NY

Fluxus was a group of artists from United States, Europe and Japan that emerged in the early 60s. Fluxus editions was a program that included affordable objects made of multiple materials and intended to convey internationally scaled ideas and activities for the group. Maciunas requested concepts from his colleagues and then he personally joined the projects to unify the aspect. The Fluxkit was one of the main formats and consists of a briefcase divided into compartments, with a selection of printed materials, boxes, film rolls, objects, animated books, anthologies of collective works, scores, instruments and games. All the objects were meant to be held, read and manipulated by their users. Designed to be portable and moderately priced, the briefcase served to introduce art into everyday experience. Fluxkit reflects a casual and interdisciplinary approach to artistic creation.

Preliminary Activity (infusion-immersion approach). The Fluxkit is presented to the students, briefly a virtual tour is taken at the time to know the artistic concerns of the society of the time. The students worked individually completing worksheets following the four-step method of art criticism and aesthetic judgment, as shown in Table 3. 
TABLE 3. Art criticism \& Aesthetic judgment analysis method

\begin{tabular}{lll} 
Steps & Key question & Main object \\
\hline Description & What do I see? & Elements \& Subjects \\
Formal analysis & How is the artwork organized? & Composition \& Design \\
Interpretation & What is happening? & Meaning \& Content \\
Decision & What do I think about the artwork? & Skill \& Technique
\end{tabular}

Divergent Thinking Activity. Students were asked to search the internet for information about the author and the work. The group was divided into teams of 4 participants and there was a brief role-play activity in which each member of the team was characterized as a friend / acquaintance / collaborator of the author and recorded with the cell phones brief interviews of the type that would be included in a documentary program about Maciunas and his work.

Convergent Thinking Activity. Students built a virtual $e$-Fluxkit, in the style of a web page, replacing each element of the original suitcase with a site or blog that symbolically represents the artifacts. Each team manufactured its own e-Fluxkit and presented it to the group for consideration to choose the model that would be offered in the modern art market or in an art gallery.

\section{Results and discussion}

In order to verify that the students of the experimental group and the control group had similar initial conditions of art and styles terminology, the results of the vocabulary PreTest in both groups were compared. Initial comparison of the 4 groups ( 3 groups EG-PreTest-T and the group CG-PreTest) where Pre-Tests had been applied revealed no significant differences in their vocabulary scores: 74.10 (EG) vs. 75.82 (CG). However, Post-Test comparison of the vocabulary scores revealed that EG-PreTest-T group showed a significantly greater improvement than CGPreTest. The vocabulary enrichment obtained in the EG sample $(+6.37 \%, \mathrm{~N}=67)$ appears to be very promising when compared to that obtained by the CG sample $(\mathrm{N}=20,+0.96 \%$, ) as indicated in Table 4.

TABLE 4. Vocabulary enrichment comparison between EG and CG scores.

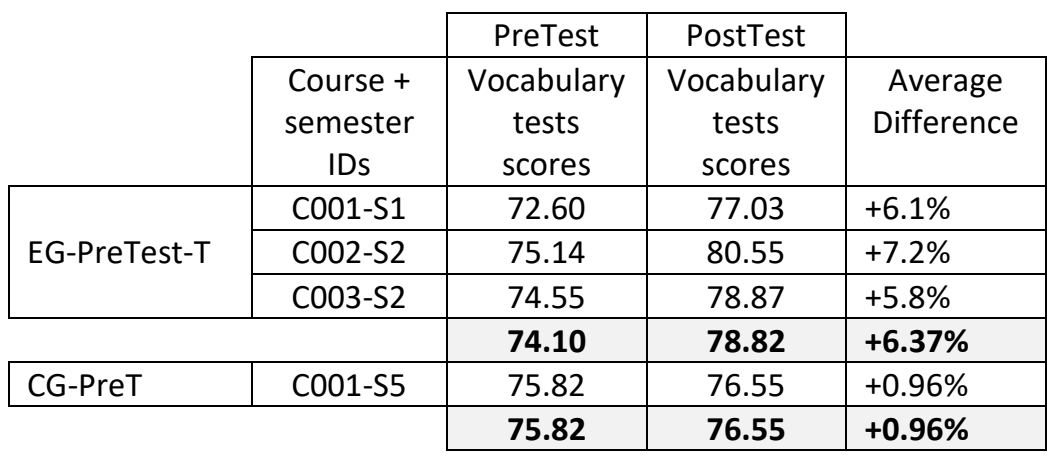


In order to determine the relationship between creative thinking and art criticism and aesthetic judgment skills, the Pearson coefficient was computed to ensure the possible correlation between results obtained in two of the PostTests: Art Crit Cards and AAC\&U Value rubrics. In addition, determination coefficient $\mathrm{R}^{2}$ value was also computed to find the percentage of the total variation in the results of the AAC\&U Value Rubrics that can be explained by the linear relationship between them and the results of the Art Crit Card self-evaluation. In all cases, and considering that the present study uses social data, the strength of the correlation was established according to Evans' criteria $\left(0.6<\mathrm{r}<0.79,36 \%<\mathrm{R}^{2}<64 \%\right)$ [33].

Table 5 shows that the Pearson coefficient for the experimental group was 0.6592 , that can be considered strongly positive, evidenced by the fact that $52 \%$ of the students that received Treatment showed this correlation. The Pearson coefficient for the control group was of -0.2450 , with $\mathrm{R}^{2}=5.6 \%$, indicating that the results obtained by the $\mathrm{CG}$ students have a very weak correlation. Table 6 indicates that students who received Treatment were able to achieve results consistent with, firstly, a wider lexical stock and a higher level of art criticism and aesthetic judgment skills $(+13.5 \%)$ and secondly, a stronger creative thinking skill (12.7\%), compared with the CG students.

TABLE 5. Comparison between EG and CG Post-Test results

\begin{tabular}{|c|c|c|c|c|}
\cline { 2 - 3 } \multicolumn{1}{c|}{} & \multicolumn{2}{c|}{ PostTest } & \multicolumn{1}{c|}{} \\
\cline { 2 - 3 } \multicolumn{1}{c|}{} & $\begin{array}{c}\text { Vocabulary } \\
\text { Tests \& Art } \\
\text { crit cards }\end{array}$ & $\begin{array}{c}\text { AAC\&U } \\
\text { Value } \\
\text { Rubrics }\end{array}$ & $\begin{array}{c}\text { Pearson } \\
\text { Coefficient } \\
\mathrm{r}\end{array}$ & $\mathrm{R}^{2}$ \\
\hline EG-PreTest-T & 83.01 & 85.26 & $\mathbf{0 . 6 5 9 2}$ & $\mathbf{5 2 \%}$ \\
\hline EG-T & 73.14 & 75.66 & $\mathbf{- 0 . 2 4 5 0}$ & $\mathbf{5 . 6 \%}$ \\
\hline CG-PreT & & & &
\end{tabular}

TABLE 6. Condensed summary of performance improvement

\begin{tabular}{|c|c|c|c|}
\hline & CG & EG & \\
\hline $\begin{array}{l}\text { Vocabulary Tests } \\
\text { \& Art crit cards }\end{array}$ & 73.14 & 83.01 & $+13.5 \%$ \\
\hline $\begin{array}{r}\text { AAC\&U } \\
\text { VALUE Rubrics }\end{array}$ & 75.66 & 85.26 & $+12.7 \%$ \\
\hline
\end{tabular}

The Post-Tests on creative thinking using AAC\&U rubrics showed that the experimental group attained $88 \%$ improvement when comparing with the students of the control group, considering the upper "Capstone" level, and a $42 \%$ decrement in the number of students who remained at the lowest "Benchmark" level of the rubric. These results are shown in Table 7. Additionally, rubric example adapted from AAC\&U VALUE Rubrics is shown in Table 8. 
TABLE 7. AAC\&U Rubrics distribution for EG and CG

\begin{tabular}{|l|c|c|c|c|}
\cline { 2 - 5 } \multicolumn{1}{c|}{} & \multicolumn{4}{c|}{ Value Rubrics } \\
\hline Groups & Capstone & \multicolumn{2}{c|}{ Milestones } & Benchmark \\
& 4 & 3 & 2 & 1 \\
\hline EG & $17 \%$ & $37 \%$ & $35 \%$ & $11 \%$ \\
\hline CG & $9 \%$ & $33 \%$ & $39 \%$ & $19 \%$ \\
\hline & $+88 \%$ & $+9 \%$ & $-8 \%$ & $-42 \%$ \\
\cline { 2 - 5 } & & & & \\
\hline
\end{tabular}

TABLE 8. Example of rubric used as PostTest. (This rubric was created using the Association of American Colleges and Universities (AAC\&U) Creative Thinking VALUE Rubric. Retrieved from https://www.aacu.org/value-rubrics)

\begin{tabular}{|c|c|c|c|c|}
\hline & $\begin{array}{c}\text { Capstone } \\
4\end{array}$ & Milest & ones & $\begin{array}{c}\text { Benchmark } \\
1\end{array}$ \\
\hline $\begin{array}{l}\text { Acquiring } \\
\text { competencies }\end{array}$ & $\begin{array}{l}\text { Reflect: Evaluates } \\
\text { creative process and } \\
\text { product using } \\
\text { domain-appropriate } \\
\text { criteria. }\end{array}$ & $\begin{array}{l}\text { Create: Creates an } \\
\text { entirely new object, } \\
\text { solution or idea that is } \\
\text { appropriate to the } \\
\text { domain. }\end{array}$ & $\begin{array}{l}\text { Adapt: Successfully } \\
\text { adapts an } \\
\text { appropriate } \\
\text { exemplar to his/her } \\
\text { own specifications. }\end{array}$ & $\begin{array}{l}\text { Model: Successfully } \\
\text { reproduces an } \\
\text { appropriate } \\
\text { exemplar. }\end{array}$ \\
\hline Taking risks & $\begin{array}{l}\text { Actively seeks out and } \\
\text { follows through on } \\
\text { untested and } \\
\text { potentially risky } \\
\text { directions or } \\
\text { approaches to the } \\
\text { assignment in the } \\
\text { final } \\
\text { product. }\end{array}$ & $\begin{array}{l}\text { Incorporates new } \\
\text { directions or } \\
\text { approaches to the } \\
\text { assignment in the final } \\
\text { product. }\end{array}$ & $\begin{array}{l}\text { Considers new } \\
\text { directions or } \\
\text { approaches without } \\
\text { going beyond the } \\
\text { guidelines of the } \\
\text { assignment. }\end{array}$ & $\begin{array}{l}\text { Stays strictly within } \\
\text { the guidelines of the } \\
\text { assignment. }\end{array}$ \\
\hline $\begin{array}{l}\text { Embracing } \\
\text { Contradictions }\end{array}$ & $\begin{array}{l}\text { Integrates alternate, } \\
\text { divergent or } \\
\text { contradictory } \\
\text { perspectives or ideas } \\
\text { fully. }\end{array}$ & $\begin{array}{l}\text { Incorporates } \\
\text { alternate, divergent or } \\
\text { contradictory } \\
\text { perspectives or ideas } \\
\text { in a } \\
\text { exploratory way. }\end{array}$ & $\begin{array}{l}\text { Includes (recognizes } \\
\text { the value of) } \\
\text { alternate, } \\
\text { divergent or } \\
\text { contradictory } \\
\text { perspectives or } \\
\text { ideas in a small way. }\end{array}$ & $\begin{array}{l}\text { Acknowledges } \\
\text { (mentions in } \\
\text { passing) alternate, } \\
\text { divergent, or } \\
\text { contradictory } \\
\text { perspectives or } \\
\text { ideas. }\end{array}$ \\
\hline
\end{tabular}

Discussion on the collaborative learning approach: The courses in which the interventions were carried out were chosen among those taught with the methodology of collaborative learning and aimed at solving engineering problems. Even in those courses that were not declared as product design and development (PDD), it was possible to verify that the incorporation of PDD process 
techniques was appropriate to solve non-design related problem [12]. Specifically, the study showed that creative thinking, both in terms of abilities and dispositions of temperament, can be exercised using the cognitive and metacognitive tools already used by the design thinking and art design methodologies.

Discussion on creative thinking assessment: Rubrics were used with the intention of evaluating and discussing learning related to students' creative thinking, not grading. The rubrics allowed to position the learning within a basic framework of expectations. The rubrics that were used were adapted from the ones prepared by the VALUE initiative (Valid Assessment of Learning in Undergraduate Education) of the Association of American Colleges and Universities (AAC\&U) [14].

Discussion on the inclusion of Art in STEM courses: The incorporation of artistic activities, such as those presented in this study, to develop creative thinking in engineering courses is a proposal of educational innovation in order to comply with the requirements of employers and accreditation agencies. This STEAM concept responds to the growing need to achieve integrated thinking in engineers. It is suggested that the incorporation of creative design into the curricular courses be carried out by trained instructors, following a sequential taxonomy of the type: creating, inventing, innovating, engineering and controlling. It is precisely in the first two stages of the process (creating and inventing) where the development of artistic activities could help to free the modality of artistic-narrative thinking developed in the previous sections [6].

\section{Conclusions}

The 21 st century engineers must be creative enough to build values and judgments and even solve ill-defined problems, taking risks and facing the lack of information and uncertainty. The results of the project suggest that the strengthening of creative thinking is closely related to the development of the ability to form appropriate judgments in different situations. The exercise of activities related to art criticism and aesthetic judgment favored a conducive teaching-learning environment, and the cognitive tools designed allowed an experience with firm links between notion and praxis. The results obtained in the different rubrics indicate a strong correlation between the practice of artistic activities and the development of a high degree of innovation, the specific disposition of the temperament necessary to assume risks and the ability to embrace contradictions by integrating divergent perspectives and ideas.

\section{Acknowledgements}

The authors would like to acknowledge the financial and the technical support of Writing Lab, TecLabs, Tecnologico de Monterrey, in the production of this work. The authors would like to acknowledge the financial support of Novus Grant with PEP no. PHHT090-17CX00001, TecLabs, Tecnologico de Monterrey, in the production of this work. The authors would like to acknowledge the students of the courses MR2003, MR2004, TE1012, TE2033 and TC1001, that so kindly and selflessly participated in this study. 


\section{References}

[1] World Economic Forum: The Future of Jobs, Employment, Skills and Workforce Strategy for the Fourth Industrial Revolution, International Report (2016). [Accessed 9 October 2018].

[2] Peterson, N.G., Mumford, M.D., Borman, W.C., Jeanneret, P.R., Fleishman, E.A., Levin, K.Y., Campion, M.A., Mayfield, M.S., Morgeson, F.P., Pearlman, K. and Gowing, M.K. Understanding work using the Occupational Information Network (O* NET): Implications for practice and research. Personnel Psychology, 54(2), 2001. pp.451-492.

[3] Ramaley, J.A., 2009. The national perspective: Fostering the enhancement of STEM undergraduate education. New Directions for Teaching and Learning, (117), 2009. pp.69-81.

[4] Spuzic, S., Narayanan, R., Abhary, K., Adriansen, H. K., Pignata, S., Uzunovic, F., \& Guang, X. The synergy of creativity and critical thinking in engineering design: the role of interdisciplinary augmentation and the fine arts. Technology in Society, 45, 2016. pp. 1-7.

[5] Yakman, G. Recognizing the "A" in STEAM Education. Middle Ground, 16(1), 2012. p.15.

[6] Watson, A. D., \& Watson, G. H. Transitioning STEM to STEAM: Reformation of engineering education. Journal for Quality and Participation, 36(3), 2013. pp 1-5. http://www.evergreen.edu/washcenter/resources/acl/iia.html. [Accessed 9 October 2018].

[7] Hayes, J. R. Cognitive processes in creativity. In Handbook of creativity. Springer, Boston, 1989, pp. 135145.

[8] Csikszentmihalyi, M. Flow and the psychology of discovery and invention. New York: Harper Collins, 1996. Vol. 56, p. 107.

[9] Lattuca, L. R., Knight, D. B., Ro, H. K., \& Novoselich, B. J. Supporting the development of Engineers' interdisciplinary competence. Journal of Engineering Education, 2017. 106(1), pp. 71-97.

[10] Caratozzolo, P., Alvarez-Delgado, A. (2018). A New Transdisciplinary Approach to Foster Soft Skills in Engineering: Using Critical Reading Micro-Workshops. In 2018 World Engineering Education ForumGlobal Engineering Deans Council (WEEF-GEDC) (pp. 1-6). WEEF2018 IEEE Proceedings.

[11] Caratozzolo, P., Alvarez-Delgado, A., and Hosseini, S. (2019). Fostering specific dispositions of Critical Thinking for student engagement in engineering. 2019 IEEE Global Engineering Education Conference (EDUCON), EDUCON2019 IEEE Proceedings.

[12] Clemente, V., Vieira, R. and Tschimmel, K. A learning toolkit to promote creative and critical thinking in product design and development through Design Thinking. In Engineering Education (CISPEE), 20162 nd International Conference of the Portuguese Society, 2012. pp. 1-6.

[13] Rawat, K. J., Qazi, W., \& Hamid, S. Creativity and education. Academic Research International, 2012. 2(2), p. 264.

[14] Allen, M. J. "Using Rubrics to Grade, Assess, and Improve Student Learning." Strengthening Our Roots: Quality, Opportunity \& Success Professional Development Day, 2014. pp. 34-35.

[15] Bruner, J. S. Actual minds, possible worlds. Harvard University Press, 2009.

[16] Dewey, John. How we think. Courier Corporation, 1997.

[17] Vygotsky, L. S. Thought and language (rev. ed.), 1986. 
[18] Ennis, R.H. Critical thinking and subject specificity: Clarification and needed research. Educational researcher, 18(3), 1989. pp.4-10.

[19] Lin, Y.S. Fostering creativity through education-a conceptual framework of creative pedagogy. Creative education, 2011. 2(03), p.149.

[20] Bensley, D. Alan, and Rachel A. Spero. "Improving critical thinking skills and metacognitive monitoring through direct infusion." Thinking Skills and Creativity 12, 2014. pp. 55-68.

[21] Caratozzolo, P., Alvarez-Delgado, A., and Hosseini, S. (2019) Strengthening critical thinking in engineering students. International Journal on Interactive Design and Manufacturing (IJIDeM), https://doi.org/10.1007/s12008-019-00559-6

[22] Egan K. The educated mind: How cognitive tools shape our understanding. University of Chicago Press; 1997.

[23] Ames, M.M. Museums in the Age of Deconstruction. Reinventing the Museum: Historical and contemporary perspectives on the paradigm shift, 81, 2004.

[24] Lohmann, J. R., Rollins, H. A., \& Joseph Hoey, J. Defining, developing and assessing global competence in engineers. European journal of engineering education, 2006. 31(1), pp. 119-131.

[25] Cieszkowski, K.Z. Glossary of art, architecture and design since 1945, by John A. Walker. London: Library Association Publishing; Boston: GK Hall. Unpaginated, (411) p. ISBN 085365639 8. Art Libraries Journal, 17(4), 1992. pp.33-35.

[26] Stack, J. Tate online strategy 2010-2012. Tate Papers, 13 (2010). https://www.tate.org.uk/art/art-terms. [Accessed 13 November 2018].

[27] Platz, J. How do you turn STEM into STEAM? Add the arts. Ohio Alliance for Arts Education. Retrieved June, 6, 2007. pp.2015. The Kennedy Center, ArtsEdge. https://artsedge.kennedy-center.org/educators. [Accessed 25 October 2018].

[28] Rhodes, T. L., \& Finley, A. P. Using the VALUE rubrics for improvement of learning and authentic assessment. Association of American Colleges and Universities, 2013.

[29] Cohen L, Manion L, Morrison K. Research methods in education. Routledge, 2002.

[30] Arnheim, R. Art and visual perception. University of California Press, 1974.

[31] Dewey, J. Art as experience. Penguin, 2005.

[32] Higgins, H. Fluxus experience. University of California Press, 2002. https://www.moma.org/interactives/exhibitions/2011/fluxus_editions/category_works/fluxkit/index.html. [Accessed 13 November 2018].

[33] Evans J.D.: Straightforward statistics for the behavioral sciences. Brooks/Cole, 1996. 